\title{
Experimental Investigations into low concentrating line axis solar concentrators for CPV applications
}

\author{
H. Singh ${ }^{\mathrm{a} *}$, M. Sabry ${ }^{\mathrm{b}, \mathrm{c}}$, D.A.G. Redpath ${ }^{\mathrm{d \dagger}}$ \\ ${ }^{a}$ Institute of Energy Futures, Brunel University London, Uxbridge, UB8 3PH, UK. \\ ${ }^{\mathrm{b}}$ Physics Dept., College of Applied Science, Umm Al Qura University, Makkah, Saudi Arabia. \\ ${ }^{\mathrm{c}}$ National Research Institute of Astronomy and Geophysics, Cairo, Egypt. \\ ${ }^{\mathrm{d} \dagger}$ Centre for Sustainable Technologies, University of Ulster, Newtownabbey, BT37 0QB, UK. ${ }^{\dagger}$ Member of \\ International Solar Energy Society. \\ *Corresponding author
}

\begin{abstract}
Solar photovoltaic conversion systems with integrated, low concentration ratio, nonimaging reflective concentrators, could be on south facing building roofs used to generate power at a lower cost than currently available proprietary systems. The experimental investigation presented by this research provides information on the optical and energy conversion characteristics of two geometrically equivalent non-imaging concentrators; a compound parabolic concentrator and a V-trough reflector. The aim was to investigate the assumption of uniform cell illumination when PV cells located on the receiver surface with their central axes are aligned parallel with the focal line of the lineaxis concentrator. Solar radiation incident was measured at the aperture and the PV cell surface using respectively a pyranometer and photodiodes at six different collector tilt angles of $0^{\circ}, 10^{\circ}, 20^{\circ}, 30^{\circ}, 40^{\circ}$ and $52^{\circ}$. The analysis of the collected experimental data presented demonstrated that the V-trough system had a more even distribution of solar radiation than the CPC and a higher optical concentration ratio (ratio of solar radiation incident on the aperture cover to that incident on the receiver) though the geometrical concentration ratio of the two collectors was equal to $2.2 \mathrm{x}$. Also, the V-trough concentrator had an electrical power output up to $17.2 \%$ higher than the CPC system at a
\end{abstract}


specific tilt angle of $30^{\circ}$. The V-trough had a consistently higher receiver plate temperature as it was reflecting larger quantities of solar radiation than the CPC. Over 17 consecutive typical summer days' similar performance was observed over the range of tilt angles studied. The development of V-trough concentrators should be preferred due to higher power production, reduced complexity, increased uniformity of illumination and lower manufacturing costs compared to CPCs.

Keywords: Photovoltaic (PV), Concentrating PV (CPV), V-trough, Compound Parabolic Concentrating (CPC), PV-Thermal, Photodiode.

\section{Introduction}

The development of non-imaging optics with their lower optical tolerances (Winston, 1974) enabled the development of line axis solar energy concentrating systems that can asymptotically approach the maximum geometric concentration of a light source for a particular angle of view. An ideal or perfect concentrator has the same fraction of solar radiation incident on the receiver as the aperture which is the thermodynamic limit of concentration (Duffie \& Beckman, 2006). Non-imaging systems are more suited to Concentrating Solar Photovoltaic (CPV) systems as they distribute incident radiation across the absorber providing the uniformity of illumination required by solar cells to avoid shading, reduced longevity, hot spots and reduced performance.

Imaging optics are more constrained, requiring solar tracking even at low concentration levels increasing the complexity, cost and maintenance needed. Systems with high concentration ratios $(>10 \mathrm{x})$ need two-axis high precision tracking with tolerances below $0.2^{\circ}$ (Leutz et al., 1999).

Non-imaging optical systems use reflective surfaces such as mirrors or lenses designed to collect extreme angular rays of incident solar radiation rather than just the axial rays collected by imaging optical systems (Welford \& Winston, 1978). The economics of solar Photovoltaic (PV) systems are improved through concentration as the area of solar cells required is reduced for CPV 
systems, though factors such as non-uniform cell illumination and higher cell operating temperatures, which degrade performance, must be investigated and solutions proposed if CPV systems are to become commercially viable. If the optical system was free, then the overall system cost could be reduced by a factor equal to the inverse of the concentration ratio. The requirement for the development of low cost specular reflective materials is imperative.

Compound Parabolic Concentrating (CPC) and V-trough reflectors, non-imaging line axis optical systems, could be attractive option for integration to photovoltaic and thermal solar arrays which are mounted on south facing roofs and walls (in the southern hemisphere arrays must face north). Such concentrating solar energy systems could be used similarly but at a lower cost than conventional solar thermal collectors, PV modules and hybrid PV-Thermal units.

CPC's and V-trough reflectors are the least complex solar reflective concentrating systems to manufacture and operate with reasonable efficiency with zero or infrequent single axis adjustments, monthly or seasonal (O'Gallagher, 2008). CPC and V-trough reflective concentrators can collect significant amount of incident diffuse solar radiation at a concentration ratio $\leq 4$; for particular stationary systems concentration ratios of up to 4 have been reported (O'Gallagher, 2008). Low concentration ratio systems (2x) have been found by previous research (O'Gallagher, 2008) to collect up to $92 \%$ of diffuse incident solar radiation making these particularly appropriate for regions experiencing high levels of diffuse radiation. The work presented by (Winston, 1974) reported that the proportion of diffuse radiation that would be collected would be the reciprocal of the concentration ratio i.e. at a concentration ratio of $2 \mathrm{X}$, $50 \%$ of the diffuse radiation incident would be collected. O'Gallagher, (2008) reported than this proportion was much higher when the solar flux incident upon the receiver was actually measured. This characteristic makes these reflective concentrators more favourable than conventional non concentrating solar energy conversion systems especially for those locations where diffuse radiation forms a significant proportion of incident solar radiation (Singh and 
Eames, 2012) as the solar flux incident on the receiver will be increased improving the quantity of useful energy collected.

PV cell performance is degraded by hot spots and partial shading (Ghitas and Sabry, 2006) and over a prolonged operation these phenomena will reduce the longevity of the cell as its encapsulation will degrade more rapidly than more uniformly illuminated cell surfaces. Few studies have reported information on the optical performance of low concentrating line-axis solar collectors, which is required to generate designs with more evenly distributed illuminance and more efficient concentrators. The optical precision required for line-axis concentrators is less stringent compared to point focussing optical concentrators, such as Fresnel lens.

It is usually assumed that the PV cells located on the receiver surface with their central axes aligned parallel with the focal line of a line-axis concentrator always receive a uniform illumination intensity along the width and length of the receiver surface. This paper investigates this assumption and reports coupled ray trace and experimental investigations into the optical and energy conversion performance of the geometrically equivalent CPC and V-trough solar collectors shown in figures 1 and 2. Focal aberrations suffered by non-imaging CPC and Vtrough reflectors were simulated using a ray-trace computer model which can account for, the acceptance half-angles for the plane perpendicular to the cross section, more accurately simulating reflector characteristics providing a more accurate prediction of the optical efficiency of the reflective concentrators in redirecting solar radiation collected by the aperture on to the receiver This value could be significantly different from that theoretically predicted using simple correlations. Predictions have been verified against experimental measurements. Accurate measurement and prediction of the illumination pattern via experimentally validated numerical models could identify hot spot locations on PV cells allowing strategies to be created to mitigate such occurrences (Hatwaambo et al., 2009). On the scale of a PV module, this would help identify the cells with the lowest power output enabling strategies to enhance the panel output to be developed. 


\section{Solar Collector Geometries Investigated}

An experimental and numerical investigation of two different non-imaging line-axis low concentrating geometries, a CPC and a V-trough, with the same receiver width $\left(\mathrm{W}_{\mathrm{r}}\right)$ of $125 \mathrm{~mm}$, was carried out at Brunel University London. The geometric concentration ratio of a CPC, $C_{C P C}$, is defined in terms of its acceptance angle $\left(\theta_{\text {accept }}\right)$ using Equation 1:

$$
C_{C P C}=\frac{1}{\sin \left(\frac{1}{2} \theta_{\text {accept }}\right)}
$$

The geometry of V-Trough concentrator is defined by its trough angle $(\theta)$ and concentration ratio $\left(C_{V}\right)$, which was calculated using Equation 2 (Fraidenraich and Almeida, 1991; Shaltout et al., 1995)

$$
C_{V} \geq 1+2 \cos 2 \theta
$$

The geometric details and dimensions of the CPC and V-trough solar energy collectors investigated are shown in figures 1 and 2 . These concentrating systems are also under consideration for future development into combined glazed PV-thermal systems, so the width of the absorber was fixed at the same size of the solar cells used $(125 \mathrm{~mm})$, further details are shown in table 1 . Low iron Pilkington Optiwhite glass aperture covers (transmissivity 0.91 , reflectance 0.08 , thickness $3 \mathrm{~mm}$ ) were used to maximise transmissivity and reduce thermal losses. Previous research by Zondag, (2008) demonstrated that glazed PVT systems are the most effective PVT configuration; single glazing reduced the electrical output by $1 \%$ but doubled the thermal output.

Two prototype non-imaging line axis solar energy concentrators, a CPC (figure 1) and Vtrough (figure 2), were manufactured using in house facilities to the geometric parameters shown 
figures 1 and 2 at Brunel University, London. Outdoor tests, under real life ambient and solar radiation conditions, were undertaken to determine the uniformity of illumination on the receiver surfaces when their central axes were aligned in parallel to the focal line of the line-axis concentrators. Typically shading of solar cells limits the overall circuit current to that generated in the shaded region. The effect of the optical performance of the concentrators' geometries on their power generation characteristics was measured and is presented in section 4 .

The geometric details and the concentration ratios of the systems shown in figures 1 and 2 were selected so that both diffuse and direct radiation incident on the collector apertures could be collected and supplied to the PV cells on the receiver at the geographical location of the experiments, London (latitude $51.5^{\circ} \mathrm{N}$ ). Each concentrator was $500 \mathrm{~mm}$ long with MiroSilver (ALANOD Ltd, 2006) reflective sheet $(0.5 \mathrm{~mm}$ thick) bonded to a polystyrene substrate forming the side and end walls. The CPC solar collector had a full height geometric concentration ratio $\left(C_{C P C}\right)$ of 3 and it was truncated to one-quarter of its full height, to $176.78 \mathrm{~mm}$, as shown in figure 1 and table 1. The V-trough concentrating system had a trough angle of $25.95^{\circ}$ as shown in figure 2 . Both concentrators had a geometrical concentration ratio of 2.2 .

Each concentrator had four series connected mono-crystalline silicon PV cells with a width of $125 \mathrm{~mm}$, length of $125 \mathrm{~mm}$ and a thickness of $0.2 \mathrm{~mm}$ attached to the flat receiver plate. The properties of the PV cells used are shown in table 2. The PV cells were adhered to the copper receiver plate with a graphite thermal pad (thermal conductivity $3.85 \mathrm{~W} / \mathrm{m} . \mathrm{K}$ ) sandwiched between the cells and the plate to increase heat transfer and ensure electrical insulation of the cells.

\section{Experimental methodology}

The experimental apparatus, figure 3 , consisted of the solar collectors described in section

2, an adjustable angular orientation table, two Kipp and Zonen SP Lite2 Pyranometers (Kipp \& Zonen, 2016), photodiodes, a digital multi-meter, and a Grant SQ 2020 Series data logger. The solar collectors were orientated East-West (E-W) and tilted about an axis parallel to their central 
long axis. The angular orientation table was employed for simultaneous longitudinal tilting of the mounted solar collectors over an angular range of $0^{\circ}$ to $40^{\circ}$ at steps of $10^{\circ}$.

Fourteen photodiodes, figure 4 , measured the intensity of the solar radiation received at the receiver area cell. Photodiodes are essentially semiconducting p-n junctions like photovoltaic cells, such that an increase of the irradiance gives a corresponding rise in the current produced by the photodiode. Surface mounted photodiodes, OSRAM SFH 2400, with a radiant sensitive area of $1 \times 1 \mathrm{~mm}^{2}$ and spectral sensitivity range of 400-1100nm were used (Osram, 2015). For these photodiodes, an increase in current is directly proportional to a rise in irradiance and linear for the majority of the I-V curve. A shunt with a fixed resistive load was joined across photodiode ends and measuring the voltage across it allowed the current to be calculated using Ohm's law. As the data logger had a measurement range of $\pm 75 \mathrm{mV}$ the voltage reading at the resistor was kept within this value.

The experiment was conducted in the month of September $\left(3^{\text {rd }}\right.$ Sep) under a cloudless sky. Each measurement period, for all 14 photodiodes, lasted a total of 9 minutes. Measurements were recorded for 6 different tilt angles $\left(0^{\circ}, 10^{\circ}, 20^{\circ}, 30^{\circ}, 40^{\circ}\right.$ and $\left.52^{\circ}\right)$ to assess the distribution of irradiance across the receiver surface in both the solar concentrators. Tilt angles were measured to an accuracy of $\pm 0.5^{\circ}$. The time recorded by the data logger and London's geographical position (latitude and longitude) were used to calculate the angles of incidence employing the solar position algorithm developed by (NREL, 2014). The mounting table shown in figure 3 was capable of tilting and holding the collectors at the required angles. The irradiance at the aperture of the solar concentrators was recorded using two pyranometers. The experimental aim was to measure the light intensity and distribution along the width of the PV cell using the photodiodes and the power developed by the PV cells under varying angles of incidence for both systems.

\section{Results and Analysis}

\subsection{Distribution of solar radiation intensity at the receiver surface}

A three-dimensional ray tracing simulation was performed to model the reflection and 
propagation of rays through optical elements. The optical performance of both concentrator systems was tested by using a known intensity of solar radiation incident on their apertures, and predicting radiation intensities received on the receiver of each system. The optical concentration ratio of the systems was calculated as the ratio of the solar radiation intensity incident on the aperture to that incident at the receiver.

The ray trace model predicted optical performance was validated against the experimentally measured data and an excellent match was found between the two, for example see figure 5 .

The spread of solar irradiance along the width of the PV surface was measured at the midlength of the concentrator cavities as shown in figures 6 and 7. The measured distribution of the solar radiation was clearly dependent on the angle of incidence; it was observed that for angles $>40^{\circ}$ the relative intensity varied from very low values in certain part of the receiver to high values in the other. The exact location (width of the receiver surface) of transition from low to high intensity depended on the collector geometry type, CPC or V-trough.

The height of the reflecting side walls $\left(\mathrm{H}_{\mathrm{V}}\right.$ and $\mathrm{H}_{\mathrm{CPC}}$, see figures 1 and 2$)$ affected the radiation intensity variation by shadowing the absorber surface more predominantly in the case of the V-trough concentrator than CPC. In the case of the V-trough cavity, the distribution was uneven at smaller angles of incidence, $1.1^{\circ}$ and $10.7^{\circ}$, as observed in figure 7 . The radiation intensity distribution observed for the CPC was comparatively uniform as shown in figure 6 .

\subsection{The Variation of Optical Concentration Ratio and Radiative Power Collection Efficiency}

Using the radiation intensities measured along the width of the receiver, the optical concentration ratio of the V-trough collector was calculated as up to $42.8 \%$ higher than that of the CPC collector over the complete range of angles of incidence studied, see figure 8. Clearly any reduction in concentration caused by truncation was compensated by the harnessing of extra radiation over incidence angles greater than the half-acceptance angle for the V-trough though this phenomenon was not observed for the CPC concentrator. Similar results were predicted by the ray 
trace simulation as well as seen in figure 8 .

\subsection{Power Generation characteristics of the solar concentrators studied}

On a sunny day, $3^{\text {rd }}$ July 2015 , the solar concentrators were horizontally orientated, at an angle of tilt $0^{\circ}$, in the E-W configuration and tested for generation characteristics such as voltage, current and electrical power produced. The solar radiation received at the aperture of the concentrators is shown in figure 9. Figure 10 shows that the V-trough concentrator produced up to, $11.9 \%$ higher levels of power than that generated by the CPC system, during periods of testing, from $10.30 \mathrm{am}$ till $2.30 \mathrm{pm}$. Figure 11 shows the amount of electrical energy generated by these two concentrators over 17 consecutive days during July 2015. These 17 days represented typical summer conditions in the UK; some days had mixed sky conditions, partly cloudy, and some completely clear sky conditions. It can be seen that the V-trough consistently performed better throughout the monitoring period than the CPC collector, for example by up to $17.2 \%$ for tilt angle of $30^{\circ}$. No method was employed to cool the receiver plates for either non imaging optical system.

T-type thermocouples, three each, were attached to the lower side of the receiver plate at $100 \mathrm{~mm}, 250 \mathrm{~mm}$ and $400 \mathrm{~mm}$ for both concentrator systems. The thermocouples were calibrated to an accuracy of $\pm 0.3 \mathrm{~K}$ using the procedure outlined in the Standard BS 1041-4 (1992). The receiver plate temperatures data recorded on $3^{\text {rd }}$ July 2015 for both concentrators under investigation is shown in figure 12. The highest temperature recorded for the $\mathrm{V}$-trough and $\mathrm{CPC}$ receiver plates was $110.3{ }^{\circ} \mathrm{C}$ and $98{ }^{\circ} \mathrm{C}$ respectively. The experimental data shown in figure 12 demonstrates that the $\mathrm{V}$ trough concentrating solar collector had a consistently higher receiver plate temperature throughout the day increasing at a greater rate than that of the CPC. This was due to its ability to intercept greater amounts of solar radiation, as evidenced by the higher cell current of the V-trough than that of the CPC system, see figure 10 . This resulted into a $11.1 \%$ greater maximum temperature than that measured for the CPC system. Such lower receiver temperature in the case of CPC collector caused the PV cells to generate a higher voltage than the V-trough panel as shown in figure 10. 


\section{Conclusions}

Experimental testing and numerical investigations compared two geometrically equivalent non-imaging optical line axis solar energy concentrators; CPC and V-trough. The results from ray tracing undertaken before the collectors were fabricated, were in good agreement with the collected experimental results indicating that the evaluated prototypes were constructed to a high standard.

The V-trough configuration was experimentally found to have superior performance collecting a greater quantity of energy. The results presented by this research have clearly shown that equal geometric concentration ratios do not have similar outputs for different optical imaging systems.

If designers compare optically equivalent (in terms of optical concentration ratio) concentrators for solar energy collection, then CPC collectors perform better theoretically, but the geometrical size and higher manufacturing cost of the CPC collectors will limit both, the application and scope for their integration within the built environment. By using a V-trough non-imaging optical solar energy concentrating system, the experimental data demonstrated how an increase in power production and a reduction in manufacturing costs is achievable. It was experimentally demonstrated that in a V-trough system the temperature of the PV receiver surface reached $110{ }^{\circ} \mathrm{C}$ on a sunny day in London, $11.1 \%$ higher than a CPC collector with a similar equivalent geometric concentration ratio. Whilst higher cell operating temperatures on one hand reduce the amount of electrical power produced by the PV element, on the other hand it offers an opportunity to harness more solar thermal energy, improving the cost effectiveness of systems making these more attractive to consumers and stimulating market demand.

Further development of such non-imaging optical solar energy concentrating systems will benefit both performance and cost effectiveness. Such technical interventions are particularly pertinent at present, when feed-in-tariff rates and other forms of government aided support are being 
reduced globally whilst solar PV industry has to expand in the domestic and commercial sectors to sustain its recent growth.

\section{References}

ALANOD Ltd, 2006. Property Sheet for Miro-Silver, Milton Keynes: Alanod Ltd.

Fraidenraich, M., Almeida, G. J., 1991. Optical properties of V-trough concentrators. Solar Energy 47 (3), 147-155.

Ghitas, A. E., Sabry, M., 2006. A study of the effect of shadowing location and area on the Si solar cell electrical parameters. Vacuum 81, 475-478.

Hatwaambo, S., Hakansson, H., Roos, A., Karlsson, B., 2009. Mitigating the non-uniform illumination in low concentrating CPCs using structured reflectors. Solar Energy Materials and Solar Cells 93 (11), 2020-2024.

Kipp \& Zonen, 2016. SP Lite2 Pyranometer. Available at: http://www.kippzonen.com/Product/9/SP-Lite2-Pyranometer\#.VvVpVP_cupo [Accessed 25 ${ }^{\text {th }}$ June, 2014].

Leutz, R., Suzuki, A., Akisawa, A., Kashiwagi, T., 1999. Design of a non imaging Fresnel lens for solar concentrators. Solar Energy 65 (6), 379-387.

NREL, 2014. MIDC SPA Calculator. Available at: http://www.nrel.gov/midc/solpos/spa.html [Accessed $5^{\text {th }}$ September, 2014].

Osram, 2015. Silicon PIN Photodiode SFH 2400 data sheet. Available at: http://www.osramos.com/Graphics/XPic2/00188627_0.pdf/SFH\%202400,\%20Lead\%20(Pb)\%20Free\%20Product\%20 -\%20RoHS\%20Compliant.pdf. [Accessed 25 ${ }^{\text {th }}$ March, 2015].

O'Gallagher, J. J., 2008. Nonimaging Optics in Solar Energy. 1 ed. San Rafael,(California): Morgan and Claypool.

Shaltout, M.A.M., Ghettas, A., Sabry, M., 1995. V-trough concentrator on a photovoltaic full tracking system in a hot desert climate. Renewable Energy 6(5-6), 527-532.

Singh, H., and Eames, P.C., 2012. Correlations for natural convective heat exchange in CPC solar collector cavities determined from experimental measurements. Solar Energy 86 (9), 24432457.

Standard (BS 1041-4), B., 1992. British Standard BS 1041-4 Temperature measurement Part 4: Guide to the selection and use of thermocouples, London: British Standards Institution.

Welford, W., and Winston, R., 1978. The optics of Nonimaging Concentrators, Academic Press, New York.

Winston, R., 1974. Principles of solar concentrators of a novel design. Solar Energy 16 (2), 89-95. 


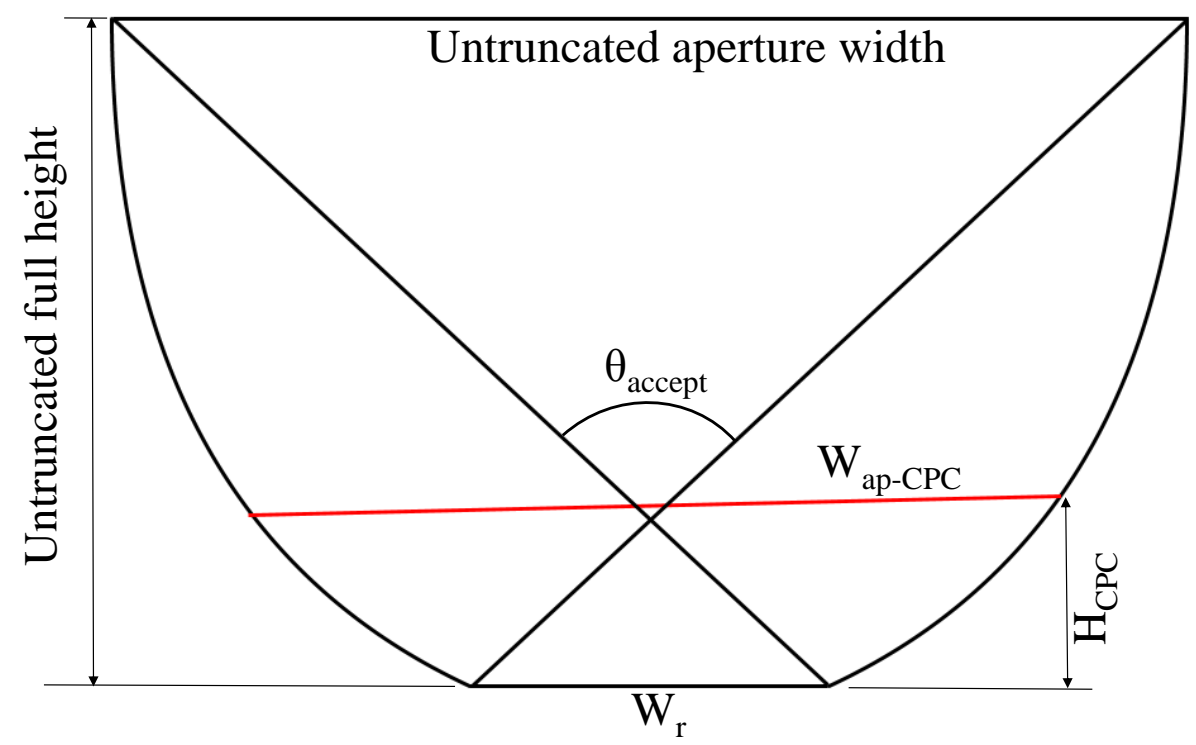

Figure 1. Schematic detailing the geometry and cross sectional view of the truncated CPC system studied (red line shows the final truncated height, one-fourth of the full height) 
Figure 2

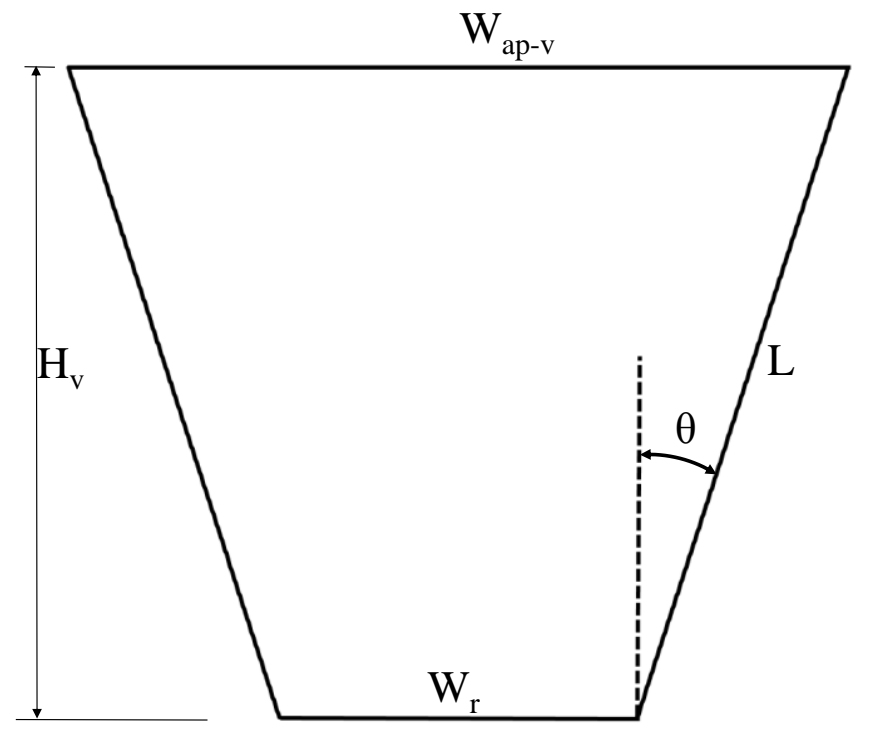

Figure 2. Schematic detailing the geometry and cross sectional view of V-trough system used for the experimental investigation 
Figure 3

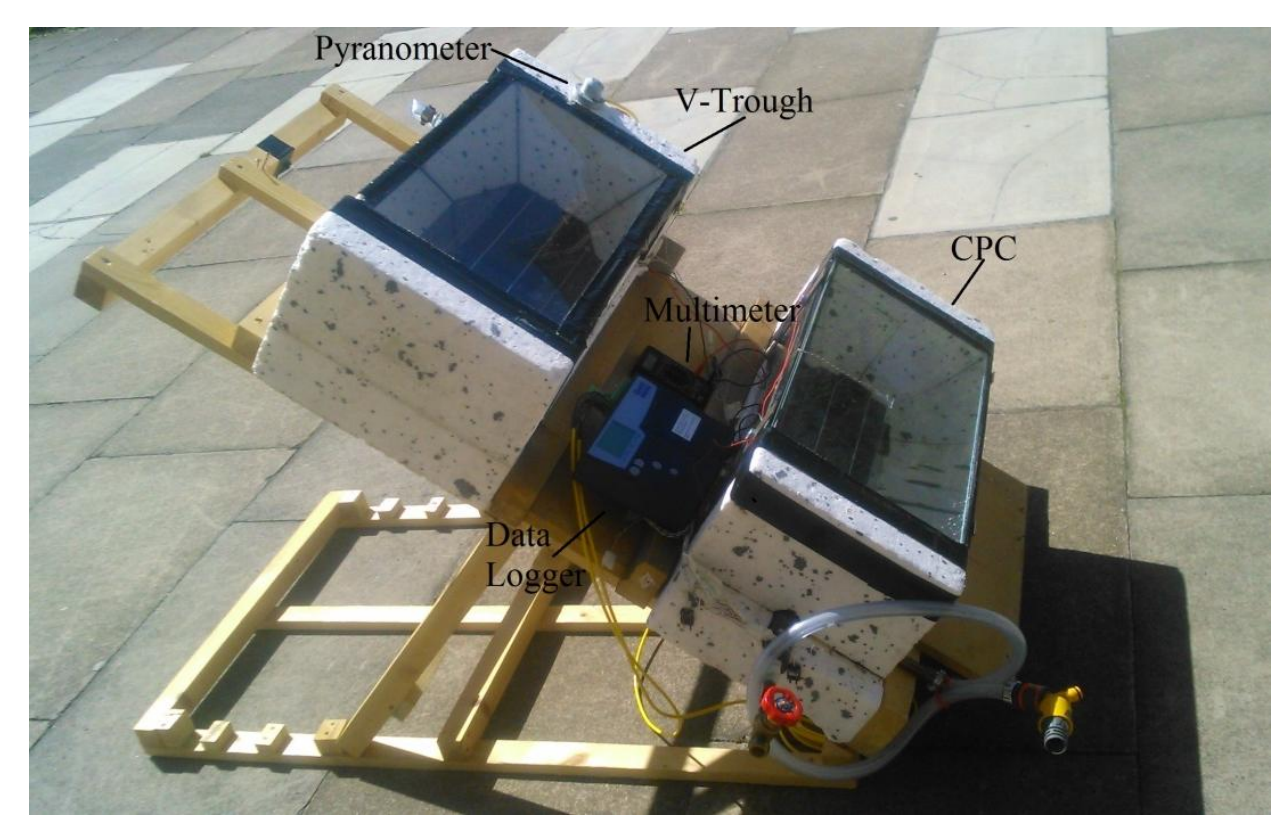

Figure 3. Experimental setup 


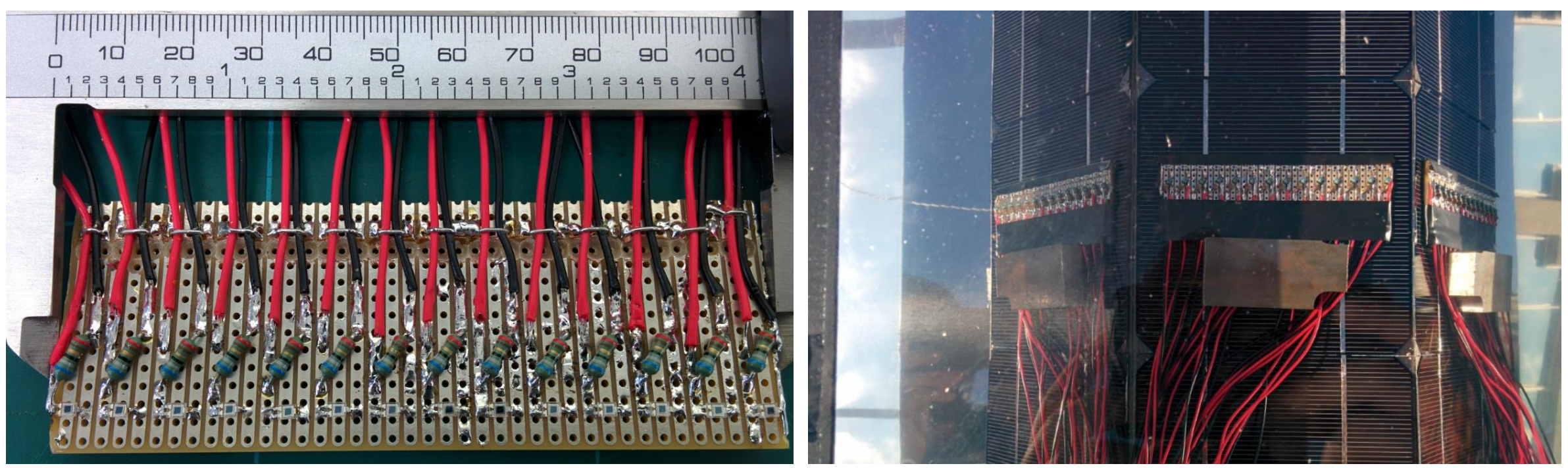

Figure 4. Positioning of photodiodes along the width of the receiver plate 

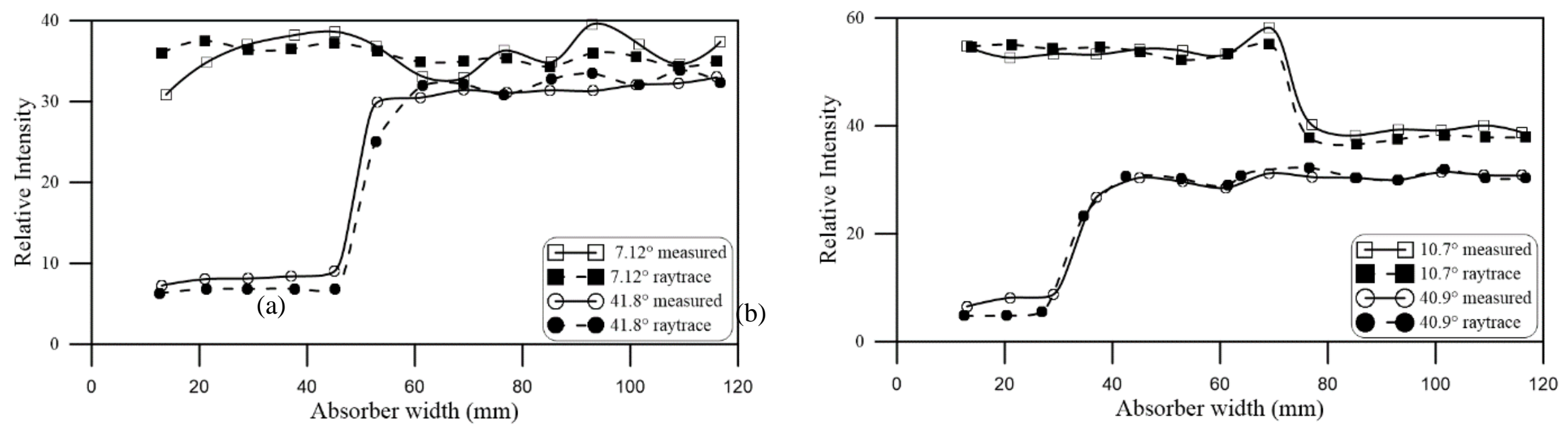

Figure 5. Comparison between ray trace modelling and experimental data measured at specific angles of incidences for (a) CPC and (b) v-trough concentrator 


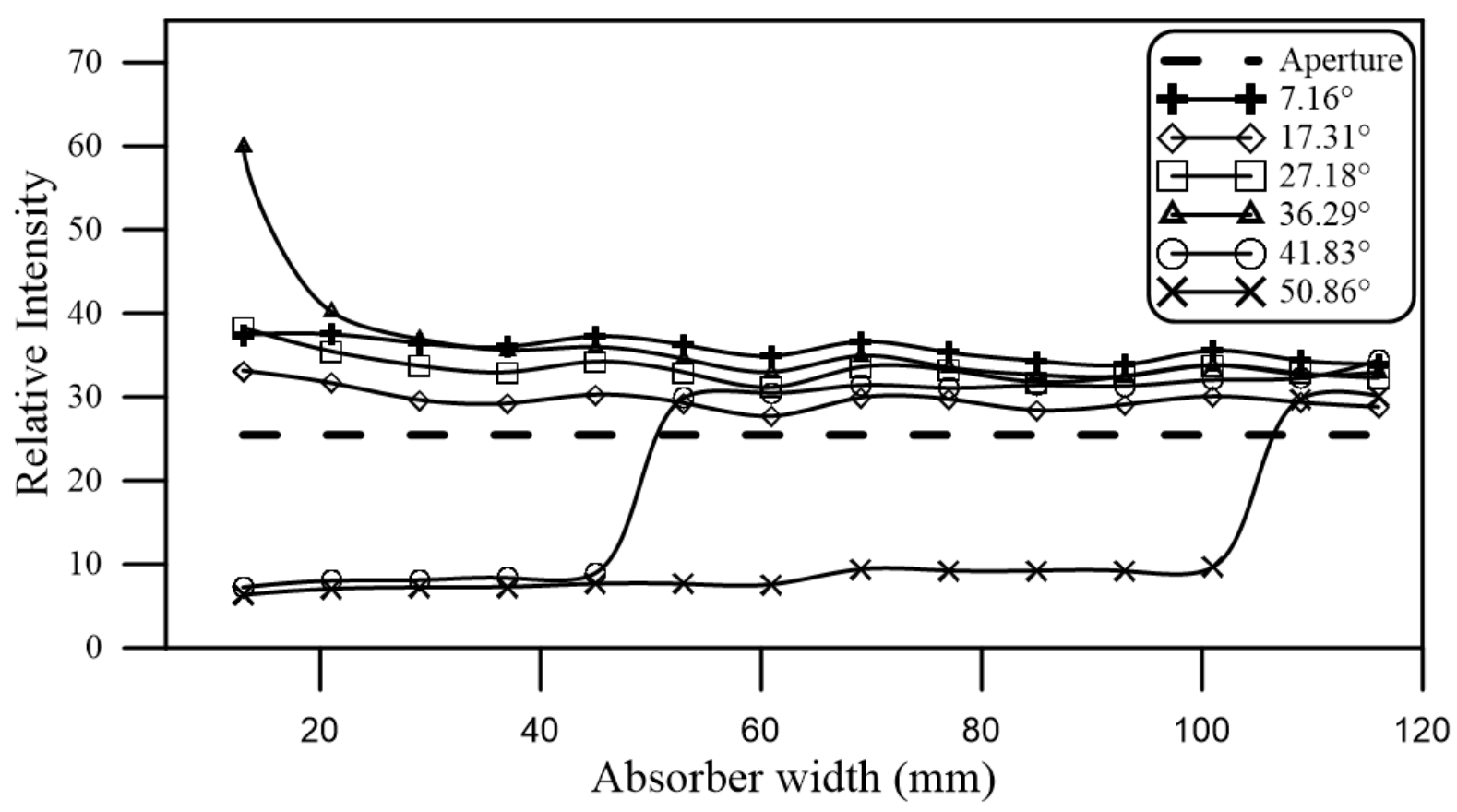

Figure 6. Solar radiation intensity on the receiver surface at mid-length of the CPC solar concentrator cavity 


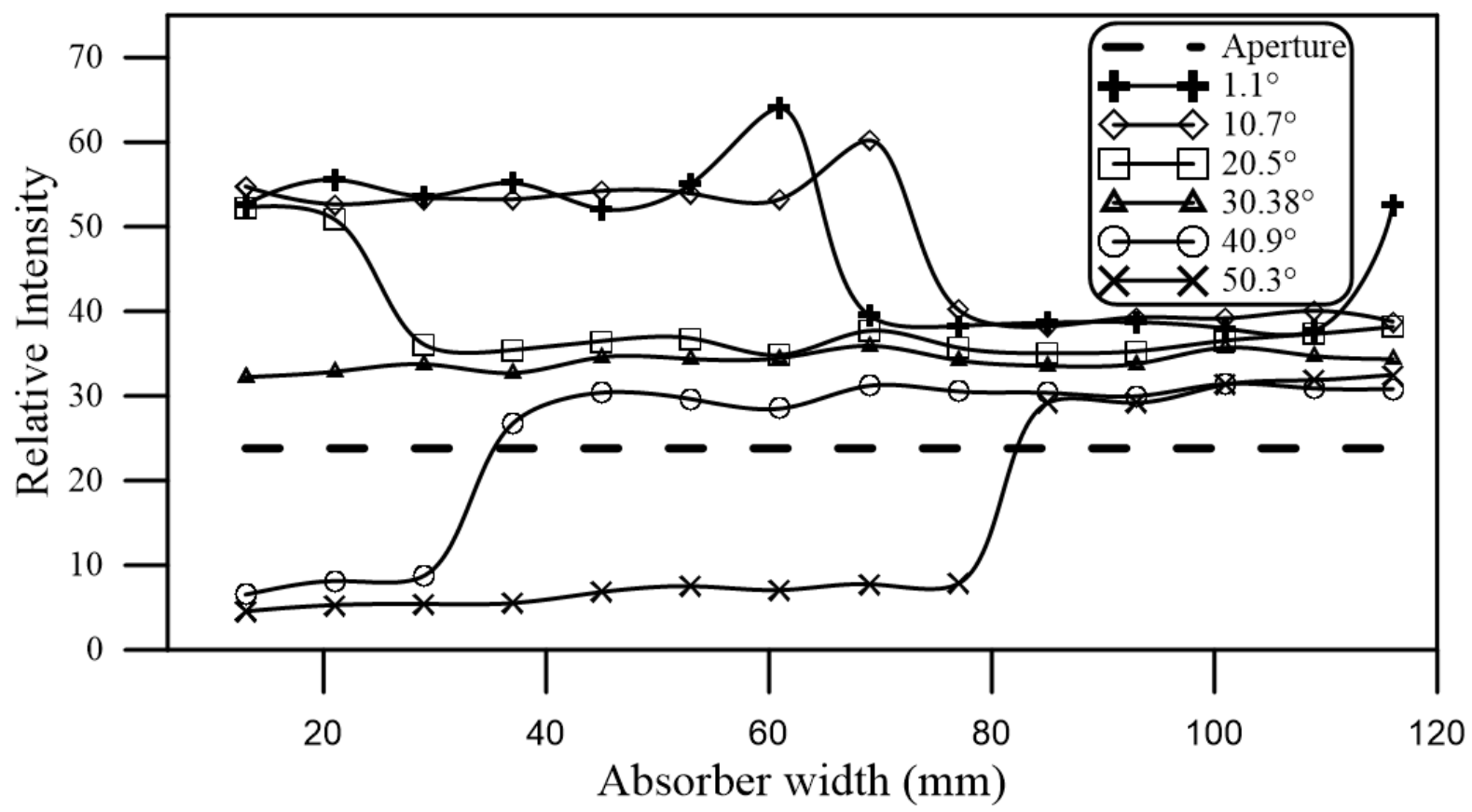

Figure 7. Solar radiation intensity measured on the receiver surface at mid-length of the Vtrough solar concentrator cavity 


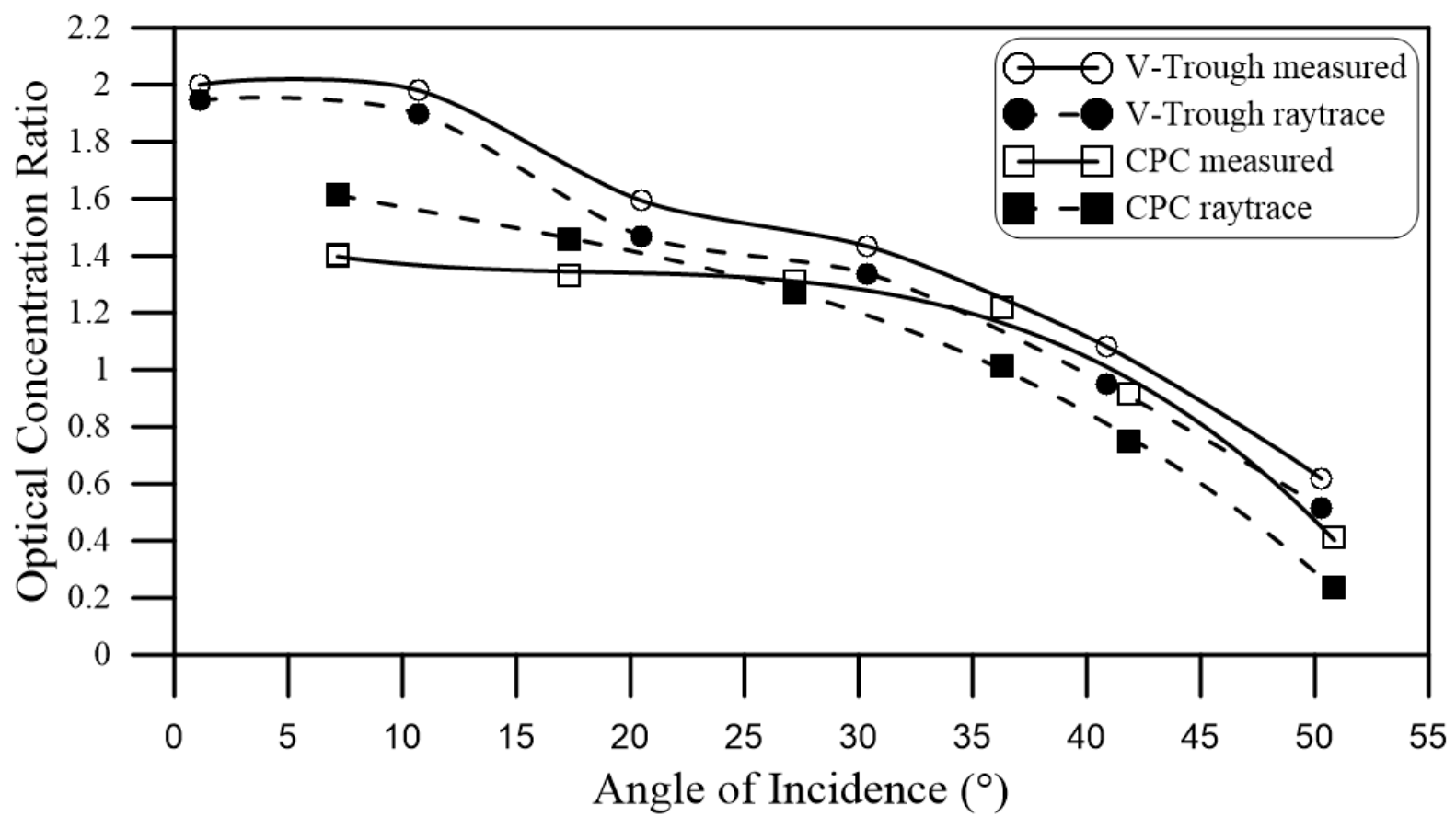

Figure 8. Optical concentration ratio of CPC and V-trough solar collectors 


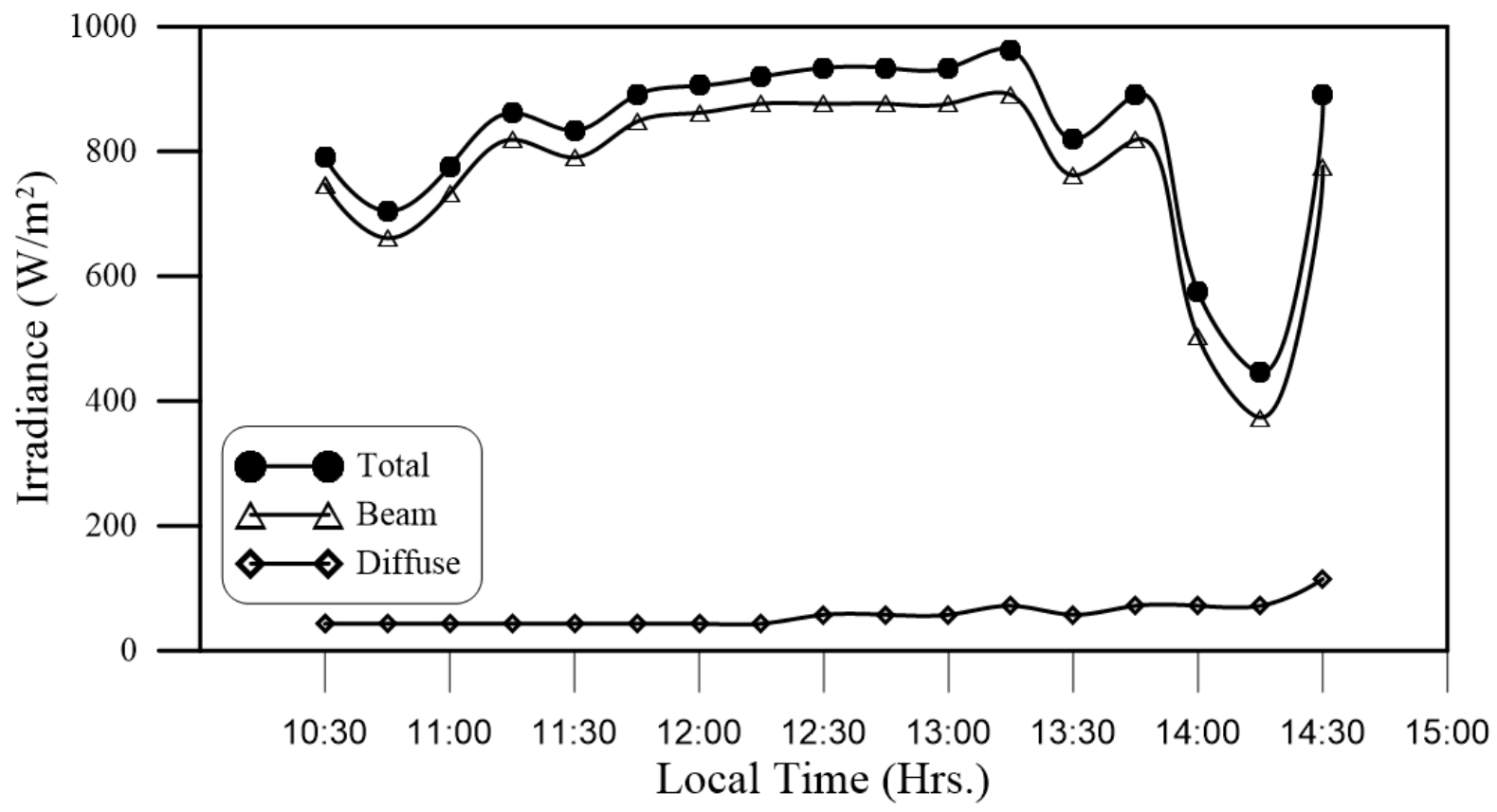

Figure 9. Solar radiation received at the horizontally held concentrator apertures on $3^{\text {rd }}$ July 2015 


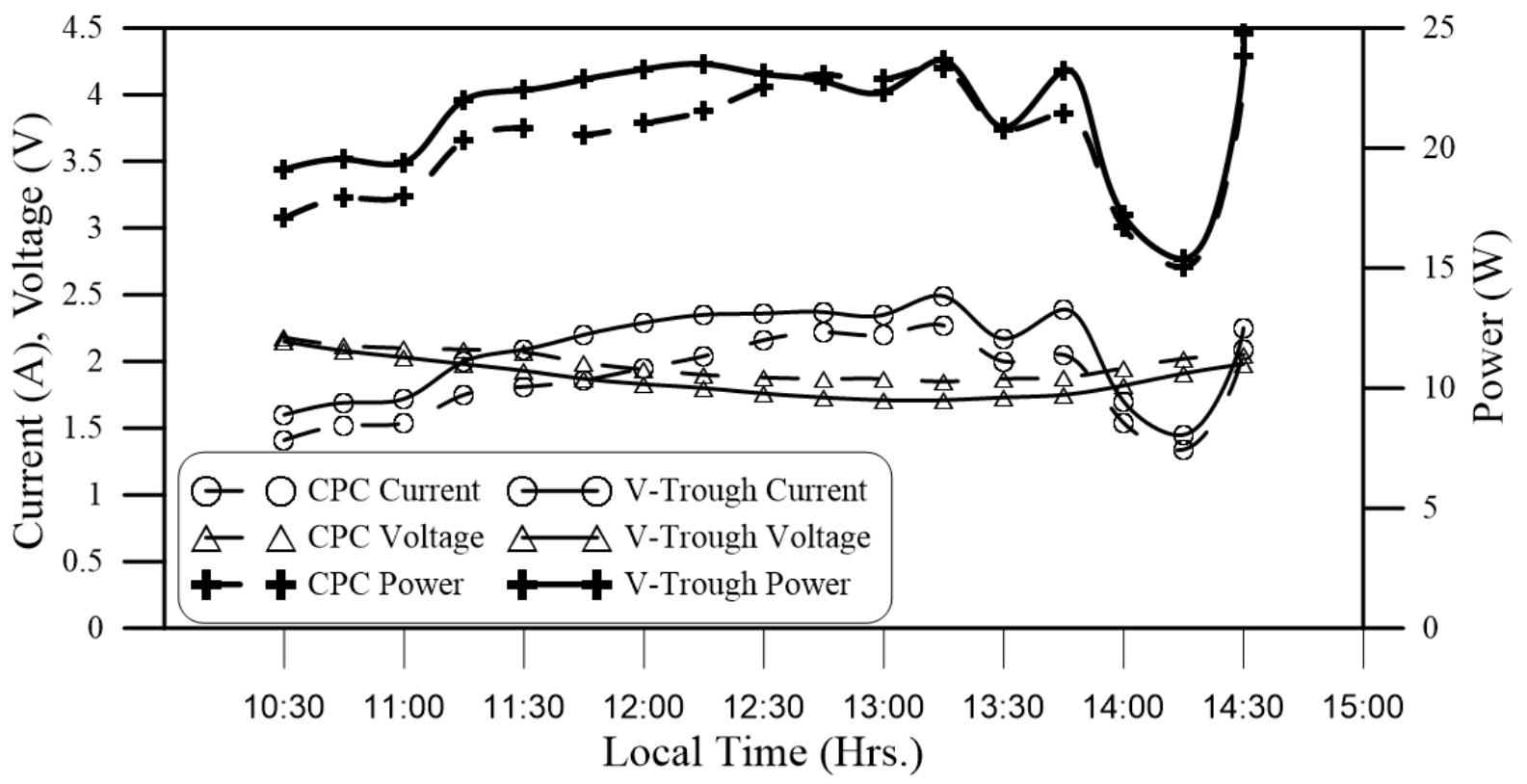

Figure 10. Generation characteristics of the horizontally held concentrators, tilt angle $0^{\circ}$ on $3^{\text {rd }}$ July 2015 


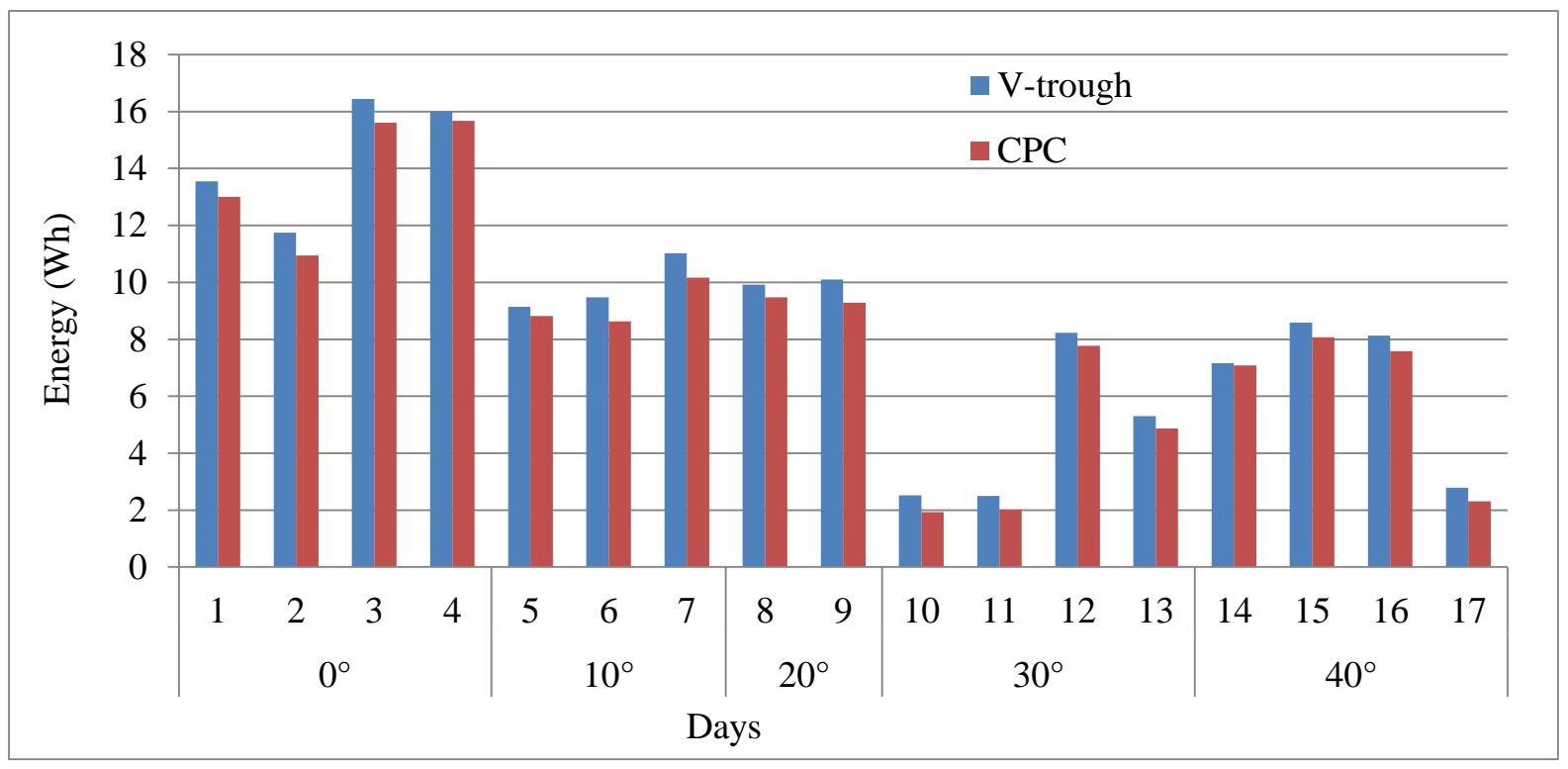

Figure 11. Energy generated by CPC and v-trough concentrators at different tilt angles 


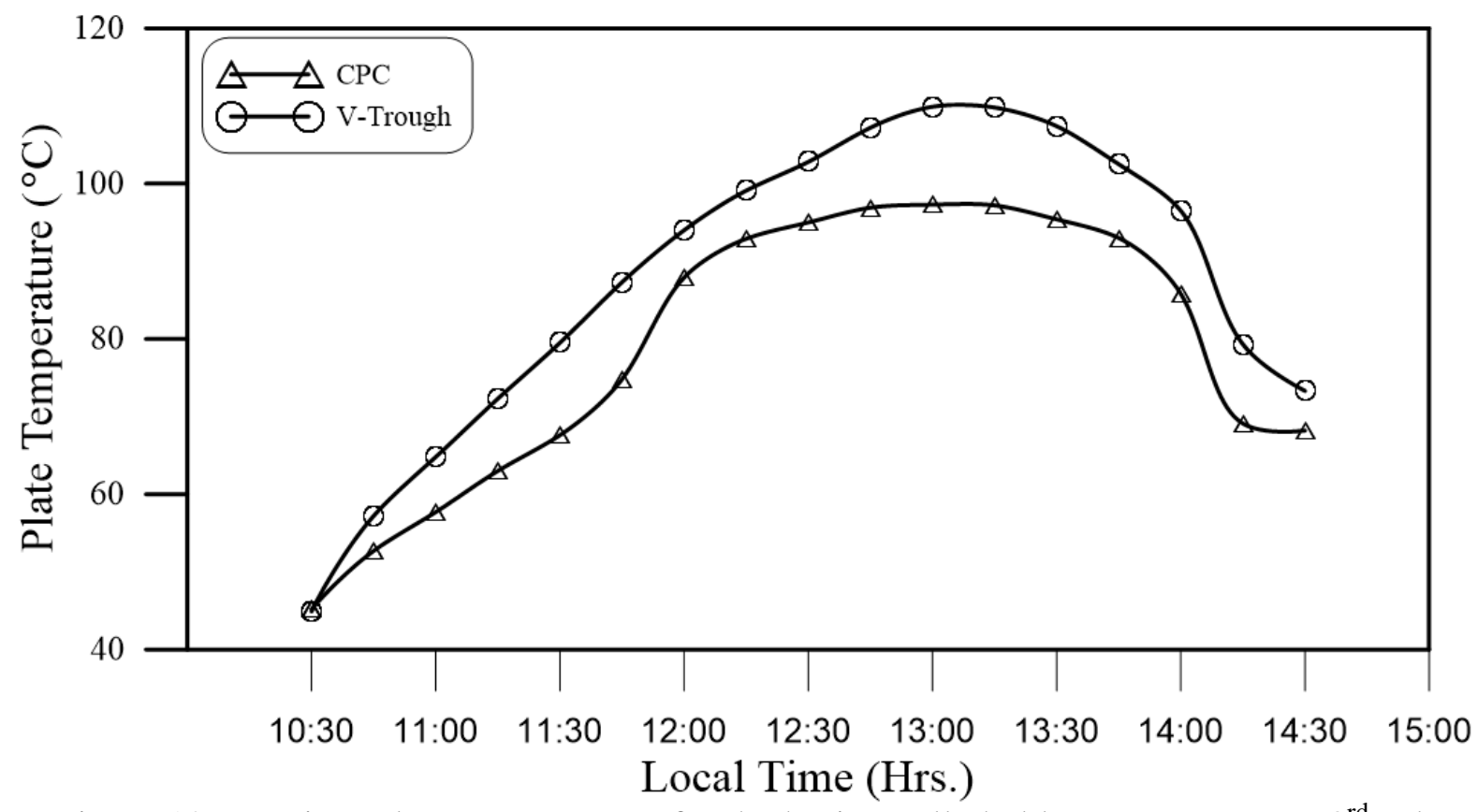

Figure 12. Receiver plate temperatures for the horizontally held concentrators on $3^{\text {rd }}$ July 2015 
Table 1. Geometric specifications of the concentrators studied (a) CPC and (b) V-trough

\begin{tabular}{|c|c|c|c|}
\hline $\begin{array}{c}\mathrm{W}_{\mathrm{r}} \\
(\mathrm{mm})\end{array}$ & $\begin{array}{c}\mathrm{H}_{\mathrm{CPC}} \\
(\mathrm{mm})\end{array}$ & $\begin{array}{c}\mathrm{W}_{\text {ap-CPC }} \\
(\mathrm{mm})\end{array}$ & $\mathrm{C}_{\mathrm{CPC}}$ \\
\hline 125 & 176.78 & 274.5 & 2.196 \\
\hline
\end{tabular}

(a)

\begin{tabular}{|l|l|l|l|l|l|}
\hline $\begin{array}{l}\mathrm{W}_{\mathrm{r}} \\
(\mathrm{mm})\end{array}$ & $\begin{array}{l}\mathrm{W}_{\text {ap-V }} \\
(\mathrm{mm})\end{array}$ & $\mathrm{C}_{\mathrm{V}}$ & $\begin{array}{l}\theta \\
\left(^{\circ}\right)\end{array}$ & $\begin{array}{l}\mathrm{L} \\
(\mathrm{mm})\end{array}$ & $\begin{array}{l}\mathrm{H}_{\mathrm{V}} \\
(\mathrm{mm})\end{array}$ \\
\hline 125 & 273.78 & 2.2 & 25.95 & 170 & 152.86 \\
\hline
\end{tabular}

(b) 
Table 2

Table 2. PV cell properties

\begin{tabular}{|l|c|c|c|c|c|}
\hline $\begin{array}{c}\text { Cell efficiency } \\
(\%)\end{array}$ & $\begin{array}{c}\mathrm{P}_{\mathrm{mp}} \\
(\mathrm{W})\end{array}$ & $\begin{array}{c}\mathrm{V}_{\mathrm{mp}} \\
(\mathrm{V})\end{array}$ & $\begin{array}{c}\mathrm{I}_{\mathrm{mp}} \\
(\mathrm{A})\end{array}$ & $\begin{array}{c}\mathrm{V}_{\mathrm{oc}} \\
(\mathrm{V})\end{array}$ & $\begin{array}{c}\mathrm{I}_{\mathrm{sc}} \\
(\mathrm{A})\end{array}$ \\
\hline 18.5 & 2.85 & 0.525 & 5.43 & 0.63 & 5.7 \\
\hline
\end{tabular}

